International Journal of Industrial Ergonomics;

40(4), 425-436. doi:DOI: 10.1016/j.ergon.2010.02.001

\title{
Estimation of the Biodynamic Responses Distributed at Fingers and Palm Based on the Total Response of the Hand-Arm System
}

\author{
Ren G. Dong ${ }^{a}$, Subhash Rakheja ${ }^{\mathrm{b}}$, Thomas W. McDowell ${ }^{\mathrm{a}}$, Daniel E. Welcome ${ }^{\mathrm{a}}$, John Z. Wu ${ }^{\mathrm{a}}$ \\ ${ }^{a}$ Engineering \& Control Technology Branch \\ National Institute for Occupational Safety and Health \\ 1095 Willowdale Road \\ Morgantown, West Virginia 26505, USA \\ ${ }^{\mathrm{b}}$ CONCAVE Research Centre, Department of Mechanical Engineering \\ Concordia University \\ 1455 de Mansonnuve Blvd. West \\ Montreal, Canada
}

\begin{abstract}
The major objective of this study is to develop a modelling method for estimating the biodynamic responses distributed at the fingers and the palm of the hand based on the total driving-point mechanical impedance of the entire hand-arm system. A five degrees-of-freedom (DOF) model with a set of constraints proposed in this study was used in the estimation. Three sets of mechanical impedance data measured at the fingers and palm of the hand were used to examine the validity of the proposed method. The estimated response distributed at the palm was consistent with the measured data even when the real part of the impedance alone was used in the modeling (coefficient of correlation, $r^{2} \geq 0.902$ ). Better agreements between the estimated and measured responses were obtained $\left(r^{2} \geq 0.929\right)$ when the magnitude and phase of the total impedance or the magnitude alone were used in the modeling estimation. In each case, the estimated response distributed at the fingers was also reliably correlated with the experimental data $\left(r^{2} \geq 0.726\right)$ but it was not as consistent with the experimental data as that distributed at the palm was. The applications of the proposed method were also demonstrated using five other sets of reported experimental data. This study also demonstrated that the modeling method may also be used to assess the quality of the experimental data in some cases. As a special application of the acceptable data identified in this study, this study also defined a 2-DOF model for the construction of a hand-arm simulator for tool tests. The results of this study and the proposed modelling method are expected to contribute to the revision of the ISO 10068 (1998).
\end{abstract}

\section{Relevance to industry}

Prolonged exposure to intensive tool vibration could cause hand-arm vibration syndrome (HAVS). An effective approach to reduce the HAVS is to reduce the intensity of the vibration exposure. The proposed modelling method and the results of this study can be used to help 
develop better tools and anti-vibration devices for reducing the exposure. The modelling study can also be used to help develop the location-specific frequency weightings for assessing the risk of the location-specific disorders induced from the hand-transmitted vibration exposure.

Key words: Modeling of hand-arm system, hand-transmitted vibration, hand, mechanical impedance, biodynamic response

\section{Introduction}

Hand-transmitted vibration exposure is one of the major hazards in the operations of many vibrating tools. The exposure could cause discomfort, injury and disorder, mainly depending on the severity of the vibration and the duration of the exposure (Griffin, 1990; ISO 5349-1, 2001). The discomfort, injury and disorder are generally location-specific. For example, vibrationinduced white finger usually occurs only in the fingers and hands, which is a unique component of the hand-arm vibration syndrome (HAVS). Besides the anatomical structures and the pathphysiological reasons, the location-specific characteristic is also likely because the vibrationinduced tissue biomechanical responses distributed in the hand-arm system must also be associated with the vibration-induced physiological and pathological effects and these essential mechanical stimuli are also location-specific (Griffin, 1990; 1994; Dong et al., 2005). Therefore, quantifying the distributed responses as functions of these influencing factors can help further understand the location-specific characteristics and develop more effective methods for assessing the risk of the vibration exposure and controlling the hand-arm vibration syndrome (Dong-JH et al., 2008). Although a considerable number of studies on the biodynamic response have been reported, their distribution in the hand-arm system has been far from sufficiently quantified and understood.

One of the major approaches for studying the biodynamic response is to measure and simulate the driving-point apparent mass and mechanical impedance (Dong et al., 2001; 2005; Rakheja et al., 2002). The hand-handle coupling relationship is vastly considered as a single-point contact in the reported studies (Mishoe and Suggs, 1977; Reynolds and Falkenberg, 1984; Lundström and Burström, 1989; Hempstock and O'Connor, 1989; Hesse, 1989; Jandak, 1989; Burström, 1990; Gurram et al., 1995a; Kihlberg, 1995; Marcotte et al. 2005). Such an approach simplifies the complexity of the hand structures and would be acceptable when the overall effect of the handarm apparent mass on the tool behavior is of concern for design analysis and/or experimental assessment of tools. This approach has also been adopted in the current ISO 10068 (1998), which was established on the basis of synthesis of some of the reported experimental data and models (Gurram et al., 1995b). This approach, however, ignores the distributed characteristics of the interaction between the hand and the tool. Although some of these single-point coupling models could fit the experimental data reasonably well, it is very difficult to associate the response of a specific element in the model with a substructure of the hand-arm system (Dong et al., 2008a), which makes it impossible to quantify and understand the response distribution. Furthermore, the vast majority of these models are not suitable for the design of a hand-arm simulator (Rakheja et al., 2002), including those recommended in the current ISO 10068 (1998) (Dong et al., 2008a). Further studies are thus necessary to improve the current standard. 
Similar to the fingertip models, proposed by $\mathrm{Wu}$ et al. (2008), a representative model of the entire hand-arm system could be developed using a finite element method. This approach, however, is computationally and technically demanding, primarily due to lack of definite nonlinear properties of different substructures and joints. While the development of such a finite element model remains a formidable task, a recent study has proposed two new mechanicalequivalent models that may be sufficient for some applications (Dong et al., 2007). Unlike the other reported models, which invariably consider one-point coupling, these new models assume two-point coupling at the hand-handle interface. The new models can effectively describe the biodynamic responses measured at both the fingers and the palm of the hand (Dong et al., 2007; 2009; Dong-JH et al., 2008), which is mostly attributed to the model structure that effectively takes into account the flexibility of the fingers relative to the remaining part of the hand. The majority of the modeling parameters could also be associated with the mechanical properties of the some substructures of the hand-arm system. Although these new models can not be used to estimate the detailed distributions of the biodynamic responses within the vibration-exposed hand-arm system, they can be used estimated the overall responses distributed in the major substructures of the hand-arm system, especially those close to the hand-handle coupling location (Dong et al., 2007; Dong-JH et al., 2008). Although these models are still crude approximations of the hand-arm system, they have shown some potential to further understanding of the hand-arm vibration syndrome. For example, the frequency weightings derived from one of the new models have shown good correlation with those observed in several epidemiological studies of the hand-arm vibration syndrome (Dong-JH et al., 2008; Malchaire et al., 2001; Tominago, 2005; Griffin et al., 2003; Bovenzi, 2009). These models may also suffice for analysis of basic mechanisms of anti-vibration devices and their further developments (Dong et al., 2009).

However, the current two-point modeling method requires the experimental data of the BRs distributed at the fingers and palm of the hand (Dong et al., 2007). Only a few sets of such data measured under limited testing conditions have been reported by one group of researchers (Dong et al., 2007; 2009; Dong-JH et al., 2008). On the other hand, many other researchers have reported the total response of the entire hand-arm system. Many different hand forces, hand and palm postures, and subjects were considered in these studies. Therefore, it is useful to find whether the distributed responses can be reasonably estimated from these abundant data. Furthermore, some of these data include only the real part or the magnitude of the total biodynamic response, (Kihlberg, 1995; Kinne et al., 2001; Besa et al., 2007). It is unknown whether the missing components of the response (phase and/or imaginary component) could be recovered from the reported partial data. It is also unknown whether the models could fit the biodynamic response of both hands frequently used in the operations of many tools (Kinne et al., 2001).

This study hypothesizes that the biodynamic responses distributed at the fingers and the palm of the hand could be estimated from the widely reported total biodynamic response measured at the hand-handle driving-point using a model-based method with a set of appropriate constraints. Furthermore, estimates of the missing components of the total measured response, namely the phase and/or imaginary part, could also be obtained using the model-based method. The primary objective of this study is to develop and evaluate such a model-based approach. Several 
examples are also presented to demonstrate the effectiveness of the proposed modelling method for estimating distributed responses. The proposed model-based approach also provided an opportunity to assess the quality of the experimental data. As a special application of the acceptable data identified in this study, a 2-DOF model of the hand-arm system is further defined using the reported two hand BR data for construction of a hand-arm system simulator.

\section{Method}

\subsection{Hand-Arm System Model}

The hand-arm system model originally reported by Dong et al., (2007) was used in this study, which is shown in Figure 1. The biodynamic response is expressed as the driving-point mechanical impedance $(Z)$, defined as

$$
Z(j \omega)=\frac{F_{I n}(j \omega)}{V(j \omega)},
$$

where $F_{I n}$ is the dynamic interaction force between the hand and the handle, $V$ is the handle vibration velocity, $j=\sqrt{-1}$ and $\omega$ is the excitation frequency.

The model formulations provided the following relationships for computing the impedance values at the fingers $\left(Z_{\text {Fingers }}\right)$, palm $\left(Z_{\text {Palm }}\right)$, and the entire hand $\left(Z_{\text {Hand }}\right)$ :

$$
\begin{aligned}
& Z_{\text {Fingers }}=\frac{\left(K_{4}+j \omega C_{4}\right)\left(Y-X_{2}\right)}{j \omega Y}+M_{4} j \omega=Z_{\text {Fingers_Re }_{-}}+j Z_{\text {Fingers_Im }_{-},}, \\
& Z_{\text {Palm }}=\frac{\left(K_{3}+j \omega C_{3}\right)\left(Y-X_{1}\right)}{j \omega Y}+M_{3} j \omega=Z_{\text {Palm_Re }_{-}+j Z_{\text {Palm_Im }_{-},},} \\
& Z_{\text {Hand }_{1}}=Z_{\text {Fingers }}+Z_{\text {Palm }_{1}}=Z_{\text {Hand_Re }_{-}}+j Z_{\text {Hand_Im }_{-},}
\end{aligned}
$$

where $Y$ is the magnitude of handle displacement excitation, $X_{1}$ and $X_{2}$ are displacement amplitudes of masses on $M_{1}$ and $M_{2}$, respectively, and subscripts $R e$ and $I m$ refer to the real and imaginary part of the complex impedance, respectively.

\subsection{Model Constraints}

Without any constraint, the solution of the total impedance in the above formulation is not unique, since it could be attained from different sets of distributed response components. The estimation of distributed responses from the total response would thus be theoretically unreliable. Consequently, additional information on the response distribution must be sought for formulation of a reliable two-point coupling model.

One possible source of additional distribution information is the mass distribution of the handarm system. Although the dynamic mass of each substructure effectively involved in a response could be affected by the applied hand forces and the hand and arm posture, the static mass distribution of an individual's hand-arm system can be assumed unchanged in the vibration exposure. The mass parameters reported by Dong-JH et al. (2008) also revealed that some of the mass elements of the model do not change greatly with changes in the hand forces and the hand action. For example, increasing the grip force from 15 to $50 \mathrm{~N}$ resulted in only marginal changes in the finger contact mass $\left(\mathrm{M}_{4}: 11\right.$ to $\left.13 \mathrm{~g}\right)$, the finger effective mass $\left(\mathrm{M}_{2}: 80\right.$ to $\left.83 \mathrm{~g}\right)$, and the palm contact mass $\left(\mathrm{M}_{3}: 25\right.$ to $\left.31 \mathrm{~g}\right)$. These mass parameters were also very similar in cases involving $50 \mathrm{~N}$ grip alone, and combined $50 \mathrm{~N}$ grip and $50 \mathrm{~N}$ push. The reported mass values 
could thus serve as important basis for defining the ranges of mass parameters for model development. Considering the possible variations in hand and arm posture, vibration types, and subjects' anthropometry, a number of limit constraints were proposed in this study for model mass parameters for a group of male subjects exerting a combined grip and push action with one hand. These include:

$$
\begin{aligned}
& 10,000 \geq M_{0} \geq 4,500 \quad \mathrm{~g} \\
& 3,000 \geq M_{1} \geq 800 \quad \mathrm{~g} \\
& 120 \geq M_{2} \geq 60 \quad \mathrm{~g} \\
& 40 \geq M_{3} \geq 20 \quad \mathrm{~g} \\
& 20 \geq M_{4} \geq 10 \quad \mathrm{~g} \\
& 0.70 M_{3} \geq M_{4} \geq 0.35 M_{3} \\
& 8.0 M_{4} \geq M_{2} \geq 5.0 M_{4}
\end{aligned}
$$

Another source of the additional distribution information is the distribution of the contact stiffness and viscous damping at the fingers and the palm of the hand. As expected, the contact stiffness of the fingers was much higher than that of the palm (Dong-JH et al., 2008). These contact stiffness and damping values are unlikely to be greatly affected by the arm posture. However, they generally increase with increase in the applied contact forces. The combined $30 \pm 15 \mathrm{~N}$ grip and $50 \pm 15 \mathrm{~N}$ push action is of primary concern in the ISO 10068 (1998). The limit constraints for this condition were established from the reported parameters in three studies (Dong et al., 2007; 2009; Dong-JH et al., 2008), and expressed as:

$$
\begin{array}{ll}
100>K_{3}>40 & \mathrm{kN} / \mathrm{m} \\
250>K_{4}>80 & \mathrm{kN} / \mathrm{m} \\
140>C_{3}>70 & \mathrm{~N}-\mathrm{s} / \mathrm{m} \\
140>C_{4}>70 & \mathrm{~N}-\mathrm{s} / \mathrm{m} \\
4.0 K_{3} \geq K_{4} \geq 1.5 K_{3} & \\
1.5 C_{3} \geq C_{4} \geq 0.85 C_{3} &
\end{array}
$$

The remaining stiffness and damping parameters of the model must also lie in a certain range. Greater uncertainties, however, would be expected in these parameters. Furthermore, the vibration transmission at low frequencies could be greatly influenced by the arm posture. A relatively wider range of limit constraints were thus imposed on these stiffness and damping parameters for the combined grip and push actions, which were estimated based on the parameters reported by Dong-JH et al. (2008), such that:

$$
\begin{aligned}
& 20>K_{0}>5 \quad \mathrm{kN} / \mathrm{m} \\
& 10>K_{1}>1 \quad \mathrm{kN} / \mathrm{m} \\
& 12>K_{2}>2 \quad \mathrm{kN} / \mathrm{m} \\
& 300>C_{0}>50 \quad \mathrm{~N}-\mathrm{s} / \mathrm{m} \\
& 300>C_{1}>50 \quad \mathrm{~N}-\mathrm{s} / \mathrm{m} \\
& 100>C_{2}>10 \quad \mathrm{~N}-\mathrm{s} / \mathrm{m}
\end{aligned}
$$




\subsection{Methods for Determining Model Parameters}

The specific values of the fifteen parameters for a given set of experimental data were determined by best fitting the model response $\left(Z_{M}\right)$ to target experimental data $\left(Z_{E}\right)$ using the widely used least root-mean-square (rms) error minimization method. Specifically, the model response $Z_{M}$ was obtained using the initial parameter vector, taken as the mid-points of the limit constraints defined in Eqs.(5)-(7). The error function $(\Delta)$ between the model and target responses is generally expressed as:

$$
\Delta=\sqrt{\frac{1}{N} \sum_{i=1}^{N}\left(Z_{M_{-} i}-Z_{E_{-} i}\right)^{2}},
$$

where $Z_{M_{-} i}$ and $Z_{E_{-} i}$ are model and target responses, respectively, corresponding to center frequency of the $i^{\text {th }}$ third octave band, and $N$ is the number bands used in the analysis. Different target functions, however, may be employed in the parameter identification task, which could affect the parameters as well as the quality of the model. The specific error function varies with the form of the available experimental data. When the responses distributed at both the fingers and palm of the hand are available, the error function $\left(\Delta_{D}\right)$ could be formulated as (Dong et al., 2007):

$$
\Delta_{D}=\Delta_{\text {Fingers } \_ \text {Re }}+\Delta_{\text {Fingers_Im }}+\Delta_{\text {Palm }_{-} R e}+\Delta_{\text {Palm_Im }_{-} \text {, }},
$$

where $\Delta_{\text {Fingers }}$ and $\Delta_{\text {Palm }}$ refer to the error functions of impedance measured at the fingers and the palm, respectively, derived using Eq. (8), and subscripts Re $_{\text {Re }}$ and _Im refer to real and impedance components of the error functions. This function is referred to as the 'distributed method, hereafter.

When the total response of the entire hand-arm system is available, the error function $\left(\Delta_{T}\right)$, referred to as the 'total impedance method', is formulated as:

$$
\Delta_{T}=\Delta_{\text {Hand_Re }_{\text {Re }}}+\Delta_{\text {Hand_Im }_{\text {Im }} \text {, }}
$$

where $\Delta_{\text {Hand }}$ is the root mean square error in the total impedance of the hand-arm system computed using Eq. (8).

When only the magnitude of the total response is available, the error function $\left(\Delta_{M}\right)$, referred to as the 'magnitude method', can be formulated as:

$$
\Delta_{M}=\Delta_{\text {Hand_Mag }_{-},},
$$

where $\Delta_{\text {Hand_Mag }}$ is magnitude of the total hand-arm system response.

An error function based upon the real part of the total response $\left(\Delta_{R}\right)$, referred to as 'real part method', could also be formulated, such that:

$$
\Delta_{R}=\Delta_{\text {Hand_Re }_{\text {Re }}} \text {. }
$$

Each of the above error functions represents a specific tactic in the determination of model parameters. Each of the error function minimization problem was solved by sequentially varying each of the fifteen parameters within the defined limit constraints. Although only minimal variations were observed in the parameters, a total of 30 cycle sequential searches were performed to assure error minimization. The resulting solutions were considered to be global minima. The error minimization program was developed in the MS Excel platform, which could be conveniently applied to solutions of other constrained error minimization problems.. 


\subsection{Evaluation of the Modeling Method}

The validation of each specific modeling tactic expressed in Eqs.(9) to (12) was performed by comparing the distributed impedances estimated from the total impedance measured in an experiment. The rms value defined in Eq.(8) and the coefficient of correlation ( $r$-square value) for the curve fit were further computed and used to assess the goodness of each tactic.

Three sets of reported experimental data were used to evaluate these four modeling tactics for estimating the distributed impedances. The body postures and hand grip orientation specified in ISO 10819 (1996) were used in each of the experiments (Dong et al., 2006; 2009). The vibration from an electric shaker was input to the right hand through an instrumented handle equipped with force sensors and accelerometers, which were used to measure the driving-point mechanical impedances distributed at the fingers and the palm of the hand along the forearm direction (see Fig. 1). The sum of the two impedances is equal to the total impedance of the entire hand-arm system (Dong et al., 2008b), which is conventionally referred to as the $\mathrm{z}_{\mathrm{h}}$-axis impedance (ISO 10068, 1998). The first set of target data was measured with six subjects exerting $50 \mathrm{~N}$ grip and $50 \mathrm{~N}$ push force on the handle exposed to a constant-velocity sinusoidal excitation in the range of 16 to $1,000 \mathrm{~Hz}$ (Dong et al., 2007). The second set of data was measured under a broad-band random excitation $(10$ to $1,000 \mathrm{~Hz}$ ) with 10 subjects applying $30 \mathrm{~N}$ grip and $45 \mathrm{~N}$ push force and it was included in the study reported by Dong-JH, (2008). The third set of data was also measured under the same broad-band random excitation as that used in the measurement of the second set of data but with six different subjects and a different instrumented handle (Dong et al., 2009).

\section{Results}

3.1 Comparison of Estimated and Measured Responses

Figures 2 to 4 illustrate comparisons of the estimated responses with the measured data using the three sets of the target data, respectively. The figures illustrate the responses of the models identified using different minimization functions, described in Eqs. (9) to (12). The results clearly show reasonably good agreements between the estimated and measured responses in the entire frequency range, irrespective of the data used in the parameter identification task. Tables 1 to 3 summarize the rms error and $r^{2}$-values of the hand, plam and fingers responses obtained from each of the parameter identification methods using the three target datasets, respectively. The tables also present the mean rms error $r^{2}$-values. The results generally show $r^{2}$-values greater than 0.9, although a few exceptions can be observed for the estimated fingers response. The residual rms errors $(\Delta)$ in each case are generally much less than the average inter-subject standard derivations (STD) of the measured data listed in Table 4, which were calculated form the original experimental data reported by Dong et al. (2007). The residual rms errors in many cases were also comparable with the average intra-subject STD.

The accuracy of the estimated distributed responses clearly relies on the modeling tactic. The first tactic $\left(\Delta_{D}\right)$ resulted in the lowest average residual rms error $(\leq 7.5 \mathrm{~N}$-s/m) and highest average $r^{2}$-value $(\geq 0.966)$, regardless of the experimental data used (see Tables 1-3). These indices describe the goodness of the fit and they are reliably better than those attained from the other tactics (paired $t$-test: $p \leq 0.031$ ). 
When the second tactic based on the total response method $\left(\Delta_{T}\right)$ is used, the highest $r^{2}$-value and the lowest residual rms values are observed in fitting of the total response (see Tables 1-3). This would be expected since the target in the error minimization function is the total response of the hand-arm system. The model responses distributed at the palm also agree reasonably well the corresponding experimental data $\left(r^{2} \geq 0.929\right)$. The model response distributed at the fingers, however, deviates from the experimental data in some of the frequency bands, but the general trends of the estimated response are consistent with those of the experimental data $\left(r^{2} \geq 0.827\right)$.

Although only partial information of the total response is used in the third tactic based on the magnitude alone $\left(\Delta_{M}\right)$, the resulting model responses show surprisingly good agreement with the total response experimental data. This is also evident from the mean residual rms error mean $r^{2}$ values (see Tables 1-3), which are quite comparable with those of the second tactic.

The responses of the model identified using the fourth tactic based upon only the real component of the response $\left(\Delta_{R}\right)$ generally show larger differences with respect to those derived from models using the other tactics. This is particularly evident from the estimated response distributed at the fingers $\left(r^{2} \geq 0.726\right)$. The results, however, suggest that model identification based on this approach also yields reasonably good agreements with the distributed measured data $\left(r^{2} \geq 0.950\right)$ (see Tables 1-3). Although the real part primarily represents the system's damping-related response, the magnitudes and phases of the entire hand model response and the response distributed at the palm are estimated reasonably well $\left(r^{2} \geq 0.902\right)$.

\subsection{Application Examples of the Modeling Method}

The five sets of typical experimental data in the $\mathrm{z}_{\mathrm{h}}$-axis reported by Hempstock and O'Connor (1989), Hesse (1989), Kihlberg (1995), Kinne et al. (2001), and Marcotte et al. (2005) were used to demonstrate the applications of the proposed modeling method. These data exhibit different characteristics because they were measured in different laboratories under different test conditions. The identified parameters of the model for each set of the experimental data, together with the natural frequencies and damping ratios of each model, are listed in Table 5. Although some of the parameter values could vary in large ranges $(>30 \%)$, they are within the limit constraints defined in Eqs. (5)-(7). Consistent with those reported in the earlier studies (Dong et al., 2007; 2009; Dong-JH et al., 2008), the three natural frequencies lie in three different regions ( 5.8 to $10.3 \mathrm{~Hz}, 33.6$ to 40.4 , and 152.8 to $251.9 \mathrm{~Hz}$ ). They respectively represent the modes associated with the upper-arm-shoulder, palm-forearm, and the fingers' structures (Dong et al., 2007). The damping ratios associated with the higher vibration modes generally tend to be higher than those of lower vibration modes.

Kinne et al. (2001) reported the magnitude of the mechanical impedance of the entire two handarm systems along the forearm direction. Therefore, the error function based upon magnitude alone $\left(\Delta_{\mathrm{M}}\right)$ was used for identifying the model parameters, while the applied hand forces were taken as $50 \mathrm{~N}$ grip and $100 \mathrm{~N}$ push. In order to facilitate the comparison of this model with other models, the parameters listed in Table 5 are considered to represent each hand equally applying $25 \mathrm{~N}$ grip and $50 \mathrm{~N}$ push. Also different from many other reported experimental data, their data was reported in the 3.15 to $400 \mathrm{~Hz}$ frequency range. Such data make the estimations of the low frequency $(7.4 \mathrm{~Hz})$ resonance responses more reliable. As shown in Fig. 5, the estimated magnitude matches reasonably well with the experimental data $\left(r^{2}=0.943, \Delta_{\text {Min_Magnitude for two }}\right.$ 
hands $=16.6 \mathrm{~N}-\mathrm{s} / \mathrm{m})$. As expected, the response at frequencies lower than $100 \mathrm{~Hz}$ is primarily distributed at the palm side. Therefore, the peak impedance of the entire hand-arm system occurring at about $40 \mathrm{~Hz}$ can be mostly associated with the resonance of the palm-forearm substructure coupled with the handle. As evidenced in the phase responses, the fingers and palm move almost exactly in phase at very low frequencies $(<6.3 \mathrm{~Hz})$, while large differences could be observed at frequencies above $40 \mathrm{~Hz}$. The large negative phase suggests that the elasticity of the hand-arm system plays a dominant role in the low frequency response.

The total response tactic was used to simulate the responses that include both the magnitude and phase of the mechanical impedance. As shown in Fig. 6, the estimated magnitude and phase responses match well with the experimental data reported by Marcotte et al. (2005) $\left(r^{2} \geq 0.880\right.$, $\Delta_{\text {Min_Magnitude }}=20.1 \mathrm{~N}-\mathrm{s} / \mathrm{m}, \Delta_{\text {Min_Phase }}=4.3 \mathrm{deg}$. $)$, except at the very high frequencies $(>630 \mathrm{~Hz})$, where the model response magnitude is higher than the measured data. The distributed responses of the resulting model, however, are similar to those observed in Fig. 4.

As shown in Fig. 7, the model results agree reasonably well with the data reported by Hempstock and O'Connor (1989) $\left(r^{2} \geq 0.915, \Delta_{\text {Min_Magnitude }}=19.3 \mathrm{~N}-\mathrm{s} / \mathrm{m}, \Delta_{\text {Min_Phase }}=6.6 \mathrm{deg}\right.$. $)$, although the the model parameters show somewhat inconsistent trend in the damping ratio associated with the highest (third) vibration mode (Table 5). Figure 8 illustrates the impedance responses of the model derived using the data reported by Hesse (1989) together with the measured data. The measured data reported in this study are largely different from the others at frequencies above $250 \mathrm{~Hz}$. Consequently, when the full range of the data from 10 to $1000 \mathrm{~Hz}$ are taken into account, the model exhibits relatively poor agreement with the measured data $\left(r^{2} \leq-0.7\right.$, $\Delta_{\text {Min_Magnitude }}=183.7 \mathrm{~N}-\mathrm{s} / \mathrm{m}, \Delta_{\text {Min_Phase }}=22.6 \mathrm{deg}$.). The model response, however, agrees reasonably well with the measured data up to $250 \mathrm{~Hz}\left(r^{2} \geq 0.918, \Delta_{\text {Min_Magnitude }}=18.7 \mathrm{~N}-\mathrm{s} / \mathrm{m}\right.$, $\Delta_{\text {Min_Phase }}=3.5 \mathrm{deg}$.).

Kihlberg (1995) reported only the real part of the mechanical impedance. Different from many other experiments, a chipping hammer and a grinder vibration spectra were used as excitations in the experiment, which resulted in comparable responses. The data measured under $40 \mathrm{~N}$ grip and $50 \mathrm{~N}$ push was considered for model identification based on the real component of the response alone $\left(\Delta_{R}\right)$. As shown in Fig. 9, the real part of the model response agrees very well with the experimental data $\left(r^{2}=0.956, \Delta_{\text {Min_Real part }}=10.9 \mathrm{~N}-\mathrm{s} / \mathrm{m}\right)$.

\section{Discussions}

The results of this study (Figs. 2-4) suggest that the driving-point mechanical impedances distributed at the fingers and the palm of the hand can be approximately estimated from the total response of the entire hand-arm system using the 5-DOF model of the hand-arm system. The missing information of the biodynamic responses can also be approximately recovered from the known response components (e.g., magnitude or real part). The modeling method proposed in this study provides a new approach to extend the applications of these experimental data, which may accelerate the quantification and understanding of the distributed biodynamic responses. The models defined in this study can be used to analyze the design of many tools and antivibration devices. The general modeling approach proposed in this study is also applicable for further model development. 
The modeling method can also be used to help evaluate the quality of the experimental data. The results of this study demonstrate that the model can reasonably fit to the experimental data that vary over a large range, as shown in Figs. 2-9. A poor fit to the experimental data would suggest a possible deficiency in the data. For example, the model results, shown in Fig. 8, do not agree with the experimental data at higher frequencies, which exhibits a rapidly increasing impedance magnitude at frequencies above $250 \mathrm{~Hz}$. The negative values impedance phase response suggests that the elasticity of the structure plays a dominant role in determining the imaginary part of the impedance. This usually occurs in the vicinity of a resonance of the system when a relatively large displacement is excited, as observed at frequencies lower than $100 \mathrm{~Hz}$ in Figs. 2-9. At very high frequencies $(>500 \mathrm{~Hz})$, however, only the skin of the hand is effectively involved in the response and the skin mass plays the dominant role in the response (Wu et al., 2008). Therefore, the skin tissues compressed against the handle surface is unlikely to have a large displacement relative to the handle surface. Then, the phase angle should be greater than $0^{\circ}$ at such high frequencies, which has also been confirmed from a finite element analysis (Wu et al., 2006). The negative phase angles of the experimental data at such frequencies could be caused by errors in the measurement system (Dong et al., 2006; Dong et al., 2008b; Adewusi et al., 2008). The experimental data reported by Hesse (1989) may thus be considered only acceptable in a limited frequency range (up to $250 \mathrm{~Hz}$ ).

The modeling approach can also be used to help identify possible errors associated with biodynamic response measurements in some cases. For example, some of the measurement errors can be detected by relaxing the limits on $\mathrm{M}_{3}$ and $\mathrm{M}_{4}$ in the model identification task. If their values are equal to or less than zero, it suggests that the tare mass cancellation of the instrumented handle used in the measurement could be overestimated and a careful examination of the instrumentation and/or the data processing method would be required. An overestimation of the tare mass could be suspected if $\mathrm{M}_{3}$ is greater than 40 grams or $\mathrm{M}_{4}$ is greater than 20 grams. One may also examine the measurement method more carefully if a natural frequency or damping ratio is largely different from the ranges listed in Table 5.

Although the 5-DOF model can characterize the measured biodynamic responses reasonably well, its implementation for development of a physical hand-arm simulator would pose technical difficulties or high cost. The acceptable experimental data identified in this study can be used to define simplified models for the design of the simulator. Two such model structures are shown in Fig. 10. Schenk et al. (2001) developed a simulator based on a one-degree-of-freedom (1-DOF) model shown in Fig. 10(a). The model parameters (Table 6) were re-defined based on the magnitude reported by Kinne et al. (2001) and the phase estimated in the current study. As shown in Fig. 11, this model can fit to the experimental data reasonably well in a certain frequency range (from 10 to $40 \mathrm{~Hz}$ in this case), depending on the selected model parameters. This model may be sufficient if only the dominant frequency of a tool is of concern. At higher frequencies, however, such a model could largely overestimate the effective mass of the handarm system, which is also shown in Fig. 11(a). This 1-DOF model can be improved by adding an additional DOF, as shown in Fig. 10(b). The parameters of this 2-DOF model are also listed in Table 6. The magnitude and phase responses of this model fit the experimental data reasonably well over a much larger frequency range $\left(r^{2}=0.873\right)$, as also shown in Fig. 11. The additional DOF may be physically implemented by inserting a block of rubber or elastic material with high 
damping property between $\mathrm{M}_{1}$ and the tool handle, which is actually a simulation of the mechanical function of the hand's palmer soft tissues.

Some of the parameters listed in Table 5 reach their bounds (Eqs.7-9), which suggests that the parameters and the distribution of the biodynamic response could vary with the selected constraints. The selection of appropriate limit constraints is thus equally important to the selection of the appropriate model structure in estimation of distributed biodynamic responses from the total response. The constraints recommended in this study may be applicable for the experimental data measured with the hand forces of $30 \pm 15 \mathrm{~N}$ grip and $50 \pm 15 \mathrm{~N}$, hand and arm postures similar to those defined in ISO 10819 (1996), and subjects with average body weight and height similar to those of the data used by Dong et al. (2007; 2009) and Dong-JH (2008). The estimation may not be acceptable if the BR measurement conditions are largely different from these conditions.

\section{Conclusions}

This study confirmed that the most reliable approach for the modeling of the biodynamic responses distributed at the fingers and the palm of the hand is to create the model using the experimental data separately measured at the fingers and the palm. Without such information, this study demonstrated that it is acceptable to approximately estimate the distributed responses from the total response using the proposed modeling method with appropriate model constraints. This study also demonstrated that if only the magnitude or real part of the total response is available, its corresponding phase angle or real part can be estimated using the available information using the modeling method. However, the reliability of the estimated distribution varies with the available information. Whereas the reliability of the estimation with the magnitude alone is comparable with that estimated with both the magnitude and phase of the total response, the estimated response is less reliable when only the real part of the mechanical impedance is used. The estimated response distributed at the palm is generally more reliable than that distributed at the fingers. This study also demonstrated that the modeling method can be used to help evaluate the experimental data in some cases.

\section{DISCLAIMERS}

The information is distributed solely for the purpose of pre dissemination peer review under applicable information quality guidelines. It has not been formally disseminated by the National Institute for Occupational Safety and Health. It does not represent and should not be construed to represent any agency determination or policy. 


\section{References}

Adewusi, S.A., Rakheja S., Marcotte P., Boileau P.-E. 2008. On the discrepancies in the reported human hand-arm impedance at higher frequencies International Journal of Industrial Ergonomics 38 (9-10), 703-714

Besa, A. J., Valero, F.J., Suner, J.L., Carballeira, J., 2007. Characterization of the mechanical impedance of the human hand-arm system: The influence of vibration direction, handarm posture and muscle tension. International Journal of Industrial Ergonomics 37, 225231.

Bovenzi, M., 2009. A prospective cohort study of exposure-response relationship for vibration induced white finger. Occup. Environ. Med. (published online. doi:10.1136/oem.2009.046128).

Burström, L., 1990. Measurement of the impedance of the hand and arm. International Archives of Occupational and Environmental Health 62 (6), 431-439.

Dong, R.G., Rakheja, S., Schopper, A.W., Han, B., and Smutz, W.P., 2001. Hand-transmitted vibration and biodynamic response of the human hand-arm: a critical review. Critical Reviews ${ }^{\mathrm{TM}}$ in Biomedical Engineering 29(4), 391-441.

Dong R.G., Wu, J.Z., Welcome, D.E., 2005. Recent advances in biodynamics of hand-arm system, Industrial Health 43: 449-471.

Dong, R.G., Welcome, D.E., McDowell, T.W., Wu, J.Z., 2006. Measurement of biodynamic response of human hand-arm system. Journal of Sound and Vibration 294(4-5), 807-827.

Dong, R.G., Dong, J.H., Wu, J.Z., Rakheja, S., 2007. Modeling of biodynamic responses distributed at the fingers and the palm of the human hand-arm system. Journal of Biomechanics 40, 2335-2340.

Dong, R.G., Welcome, D.E., Wu, J.Z., and McDowell, T.W., 2008a. Development of hand-arm system models for vibrating tool analysis and test rig construction. Noise Control Engineering Journal 56(1), 35-44.

Dong, R.G., Welcome, D.E., McDowell, T.W., and Wu, J.Z., 2008b. Analysis of handle dynamics-induced errors in hand biodynamic measurements. Journal of Sound and Vibration 318(4-5), 1313-1333.

Dong, J.H., Dong, R.G., Rakheja, S., Welcome, D.E., McDowell, T.W., and Wu, J.Z., 2008. A method for analyzing absorbed power distribution in the hand and arm substructures when operating vibrating tools. Journal of Sound and Vibration 311: 1286-1309.

Dong, R.G., McDowell, T.W., Welcome, D.E., Warren, C., Wu, J.Z., and Rakheja, S., 2009. Analysis of anti-vibration gloves mechanism and evaluation methods. Journal of Sound and Vibration 321: 435-453.

Griffin, M.J., 1990. Handbook of Human Vibration. Academic Press, London.

Griffin, M.J., 1994. Foundations of hand-transmitted vibration standards, Nagoya J. of Med. Sci., Suppl. 57: 147-164.

Griffin, M., Bovenzi, M., Nelson, C.M., 2003. Dose-response patterns for vibration-induced white finger, Occupational and Environmental Medicine 60: 16-26.

Gurram, R., Rakheja, S., Gouw, G.J., 1995a. Mechanical Impedance of the human hand-arm system subject to sinusoidal and stochastic excitations. International Journal of Industrial Ergonomics 16 (2), 135-145.

Gurram, R., Rakheja, S., and Brammer, A.J., 1995b. Driving-point mechanical impedance of the human hand-arm system: Synthesis and model development. Journal of Sound and Vibration 180, 437-458. 
Hempstock, T.I., and O'Connor D.E., 1989. Measurement of impedance of hand-arm system. Proceedings of the Institution of Acoustics 11: 483-490.

Heese, M., Die Antwort des Hand-Arm Systems auf stochastische Erregung und ihre Anwendung im Schwingungsschutz. Ph.D. Dissertation, Universität Dortmund.

ISO10819, 1996: Mechanical vibration and shock - hand-arm vibration - method for the measurement and evaluation of the vibration transmissibility of gloves at the palm of the hand. International Organization for Standardization, Geneva, Switzerland.

ISO 5349-1, 2001. Mechanical vibration and shock - Measurement and evaluation of human exposure to hand-transmitted vibration - Part 1: General guidelines. International Organization for Standardization, Geneva, Switzerland.

ISO 10068, 1998. Mechanical vibration and shock - Free, mechanical impedance of the human hand-arm system at the driving point. International Organization for Standardization, Geneva, Switzerland.

Jandak, Z., 1989. Energy transfer to hand-arm system at exposure to vibration. Proceedings of the $5^{\text {th }}$ International Conference on Hand-Arm Vibration, Kawasaki, Japan, 49-54.

Kihlberg, S., 1995. Biodynamic response of the hand-arm system to vibration from an impact hammer and a grinder, International Journal of Industrial Ergonomics 16, 1-8.

Kinne, J., Latzel, K., Schenk, T.H., 2001. Application of two-hand impedance as basis for mechanical modeling. Proceedings of the $9^{\text {th }}$ International Conference on Hand-Arm Vibration, Nancy, France, 113-118.

Lundström, R., and Burström L., 1989. Mechanical impedance of the human hand-arm system. International Journal of Industrial Ergonomics 3, 235-242.

Marcotte, P, Aldien, Y, Boileau, P.E., Rakheja, S., Boutin, J., 2005. Effect of handle size and hand-handle contact force on the biodynamic response of the hand-arm system under zhaxis vibration. J. of Sound and Vibration 283(3-5), 1071-1091.

Malchaire J., Piette A., Cock N., 2001. Associations between hand-wrist musculoskeletal and sensorineural complaints and biomechanical and vibration work constraints, Annals of Occupational Hygiene 45: 479-491.

Mishoe, J.W., and Suggs C.W., 1977. Hand-arm vibration Part II: vibrational responses of the human hand. Journal of Sound and Vibration 53, 545-558.

Rakheja, S., Wu, J.Z., Dong, R.G. and Schopper, A.W., 2002. A comparison of biodynamic models of the human hand-arm system for applications to hand-held power tools. Journal of Sound and Vibration 249(1), 55-82.

Reynolds, D.D. and Falkenberg, R.J., 1984. A study of hand vibration on chipping and grinding operators, Part II: Four-degree-of-freedom lumped parameter model of the vibration response of the human hand, Journal of Sound and Vibration 95: 499-514.

Schenk, T.H., Kinne, J., Gillmeister, F., 2001. A real hand-arm model for use in hand-held tool test stands for vibration studies. Proceedings of the $9^{\text {th }}$ International Conference on HandArm Vibration, Nancy, France, 121-127.

Tominago, Y., 2005. New frequency weighting of hand-arm vibration, Industrial Health 43: 509515.

Wu, J.Z., Dong, R.G., Welcome, D.E., 2006. Analysis of the Point Mechanical Impedance of Fingerpad in Vibration. Medical Engineering \& Physics 28, 816-826.

Wu, J.Z., Welcome, D.E., Krajnak, K., and Dong, R.G., 2008. Three-dimensional finite element simulations of the dynamic response of a fingertip to vibration. Journal of Biomechanical Engineering 130(5): 054501-1/8. 


\section{List of Tables and Figures:}

Table 1: Correlation coefficients $\left(r^{2}\right.$-values) and residual rms errors $(\Delta$-values) of the estimated mechanical impedances relative to the first set of experimental data reported by Dong et al. (2007).

Table 2: Correlation coefficients $\left(r^{2}\right.$-values) and residual rms errors ( $\Delta$-values) of the estimated mechanical impedances relative to the second set of experimental data reported by Dong-JH et al. (2008).

Table 3: Correlation coefficients $\left(r^{2}\right.$-values) and residual rms errors ( $\Delta$-values) of the estimated mechanical impedances relative to the third set of experimental data reported by Dong et al. (2009).

Table 4: The average inter- and intra-subject standard derivations (STDs) calculated from the data reported by Dong et al., (2009) (Note: The average inter-subject STD is the average of the inter-subject STDs at the one-third octave band frequencies. The average intra-subject STD is the average of the intra-subject STDs at the one-third octave band frequencies).

Table 5: Parameters of the 5-DOF model shown in Fig. 1 and defined using the experimental data reported by Kinne et al. (2001), Marcotte et al. (2005), Hempstock and O’Connor (1989), Hesse (1989), and Kihlberg (1995), respectively.

Table 6: Parameters of the 1-DOF and 2-DOF models shown in Fig. 10 and defined using the magnitude reported by Kinne et al. (2001) and the phase estimated in this study (Fig. $5)$.

Fig. 1: The 5-DOF model structure used in this study.

Fig. 2: Comparisons of the estimated magnitudes and phases of the driving-point mechanical impedances distributed at the fingers and palm of the hand with those reported by Dong et al. (2007).

Fig. 3: Comparisons of the estimated magnitudes and phases of the driving-point mechanical impedances distributed at the fingers and palm of the hand with those reported by Dong-JH et al. (2008).

Fig. 4: Comparisons of the estimated magnitudes and phases of the driving-point mechanical impedances distributed at the fingers and palm of the hand with those reported by Dong et al. (2009).

Fig. 5: Estimations of the mechanical impedances distributed at the fingers and palm of the hand from the magnitude response reported by Kinne et al. (2001). 
Fig. 6: Estimations of the mechanical impedances distributed at the fingers and palm of the hand from the magnitude and phase responses reported by Marcotte et al. (2005).

Fig. 7: Estimations of the mechanical impedances distributed at the fingers and palm of the hand from the magnitude and phase responses reported by Hempstock and O'Connor (1989).

Fig. 8: Estimations of the mechanical impedances distributed at the fingers and palm of the hand from the magnitude and phase responses reported by Hesse (1989).

Fig. 9: Estimations of the mechanical impedances distributed at the fingers and palm of the hand from the real part response reported by Kihlberg (1995).

Fig. 10: Two practical model structures for the design and construction of a hand-arm system simulator.

Fig. 11: Comparisons of the estimated apparent mass magnitude and phase with those derived from the mechanical impedance data shown in Fig. 5 and reported by Kinne et al. (2001). 
Table 1

\begin{tabular}{|c|c|c|c|c|c|c|c|c|c|}
\hline \multirow[b]{2}{*}{ Method } & \multirow[b]{2}{*}{$\begin{array}{l}\text { Impedance } \\
\text { measure }\end{array}$} & \multicolumn{2}{|c|}{ Hand } & \multicolumn{2}{|c|}{ Palm } & \multicolumn{2}{|c|}{ Fingers } & \multicolumn{2}{|c|}{ Average } \\
\hline & & $r^{2}$-value & $\begin{array}{l}\text { rms } \\
\text { error }\end{array}$ & $\begin{array}{c}R^{2}- \\
\text { value }\end{array}$ & $\begin{array}{l}\text { rms } \\
\text { error }\end{array}$ & $r^{2}$-value & $\begin{array}{l}\text { rms } \\
\text { error }\end{array}$ & $r^{2}$-value & $\begin{array}{l}\text { rms } \\
\text { error }\end{array}$ \\
\hline 1. & $\begin{array}{l}\text { Magnitude } \\
(\mathrm{N}-\mathrm{s} / \mathrm{m})\end{array}$ & 0.974 & 16.1 & 0.990 & 10.2 & 0.990 & 7.1 & 0.984 & 7.5 \\
\hline mentive & $\begin{array}{l}\text { (deg.) } \\
\text { Magnitude }\end{array}$ & 0.988 & 3.0 & 0.989 & 4.5 & 0.971 & 3.8 & & \\
\hline $\begin{array}{l}\text { Total } \\
\text { method }\end{array}$ & $\begin{array}{l}(\mathrm{N}-\mathrm{s} / \mathrm{m}) \\
\text { Phase }\end{array}$ & 0.975 & 15.7 & 0.976 & 17.5 & 0.964 & 13.5 & 0.968 & 10.9 \\
\hline 3. & $\begin{array}{l}\text { (deg.) } \\
\text { Magnitude }\end{array}$ & 0.995 & 2.0 & 0.988 & 4.3 & 0.907 & 12.4 & & \\
\hline $\begin{array}{l}\text { Magnitude } \\
\text { method }\end{array}$ & $\begin{array}{l}(\mathrm{N}-\mathrm{s} / \mathrm{m}) \\
\text { Phase }\end{array}$ & 0.990 & 10.4 & 0.987 & 13.0 & 0.992 & 11.1 & 0.978 & 8.4 \\
\hline $\begin{array}{l}4 . \\
\text { Real-part } \\
\text { method }\end{array}$ & $\begin{array}{l}\text { (deg.) } \\
\text { Magnitude } \\
(\mathrm{N}-\mathrm{s} / \mathrm{m}) \\
\text { Phase }\end{array}$ & 0.963 & 16.3 & $\begin{array}{l}0.984 \\
0.983\end{array}$ & 18.2 & $\begin{array}{l}0.953 \\
0.980\end{array}$ & 17.8 & 0.948 & 12.7 \\
\hline & (deg.) & 0.961 & 6.3 & 0.980 & 6.5 & 0.808 & 10.9 & & \\
\hline
\end{tabular}


Table 2

\begin{tabular}{|c|c|c|c|c|c|c|c|c|c|}
\hline \multirow[b]{2}{*}{ Method } & \multirow[b]{2}{*}{$\begin{array}{l}\text { Impedance } \\
\text { measure }\end{array}$} & \multicolumn{2}{|c|}{ Hand } & \multicolumn{2}{|c|}{ Palm } & \multicolumn{2}{|c|}{ Fingers } & \multicolumn{2}{|c|}{ Average } \\
\hline & & $r^{2}$-value & $\begin{array}{l}\text { rms } \\
\text { error }\end{array}$ & $r^{2}$-value & $\begin{array}{l}\text { rms } \\
\text { error }\end{array}$ & $r^{2}$-value & $\begin{array}{l}\text { rms } \\
\text { error }\end{array}$ & $r^{2}$-value & $\begin{array}{l}\text { rms } \\
\text { error }\end{array}$ \\
\hline $\begin{array}{l}1 . \\
\text { Distributed } \\
\text { method }\end{array}$ & $\begin{array}{l}\text { Magnitude } \\
(\mathrm{N}-\mathrm{s} / \mathrm{m}) \\
\text { Phase }\end{array}$ & 0.978 & 6.5 & 0.978 & 6.7 & 0.998 & 1.7 & 0.969 & 4.1 \\
\hline 2. & $\begin{array}{l}\text { (deg.) } \\
\text { Magnitude }\end{array}$ & 0.984 & 2.1 & 0.986 & 3.0 & 0.891 & 4.7 & & \\
\hline $\begin{array}{l}\text { Total } \\
\text { method }\end{array}$ & $\begin{array}{l}(\mathrm{N}-\mathrm{s} / \mathrm{m}) \\
\text { Phase } \\
\text { (deg.) }\end{array}$ & $\begin{array}{l}0.994 \\
0.994\end{array}$ & $\begin{array}{l}3.6 \\
1.3\end{array}$ & $\begin{array}{l}0.929 \\
0.979\end{array}$ & $\begin{array}{l}13.0 \\
4.5\end{array}$ & $\begin{array}{l}0.944 \\
0.827\end{array}$ & $\begin{array}{l}11.0 \\
7.7\end{array}$ & 0.945 & 6.8 \\
\hline $\begin{array}{l}3 . \\
\text { Magnitude } \\
\text { method }\end{array}$ & $\begin{array}{l}\text { Magnitude } \\
\text { (N-s/m) } \\
\text { Phase }\end{array}$ & 0.995 & 3.3 & 0.942 & 11.0 & 0.962 & 9.1 & 0.937 & 6.8 \\
\hline $\begin{array}{l}4 . \\
\text { Real-part } \\
\text { method }\end{array}$ & $\begin{array}{l}\text { (deg.) } \\
\text { Magnitude } \\
(\mathrm{N}-\mathrm{s} / \mathrm{m}) \\
\text { Phase } \\
\text { (deg.) }\end{array}$ & $\begin{array}{l}0.943 \\
0.963 \\
0.908 \\
\end{array}$ & $\begin{array}{r}4.3 \\
10.3 \\
5.3 \\
\end{array}$ & $\begin{array}{l}0.966 \\
0.946 \\
0.902 \\
\end{array}$ & $\begin{array}{c}5.7 \\
20.8 \\
8.5 \\
\end{array}$ & $\begin{array}{l}0.816 \\
0.846 \\
0.726 \\
\end{array}$ & $\begin{array}{r}7.6 \\
24.3 \\
9.2 \\
\end{array}$ & 0.882 & 13.1 \\
\hline
\end{tabular}


Table 3

\begin{tabular}{|c|c|c|c|c|c|c|c|c|c|}
\hline \multirow[b]{2}{*}{ Method } & \multirow[b]{2}{*}{$\begin{array}{c}\text { Impedance } \\
\text { measure }\end{array}$} & \multicolumn{2}{|c|}{ Hand } & \multicolumn{2}{|c|}{ Palm } & \multicolumn{2}{|c|}{ Fingers } & \multicolumn{2}{|c|}{ Average } \\
\hline & & $r^{2}$-value & $\begin{array}{l}\text { rms } \\
\text { error }\end{array}$ & $r^{2}$-value & $\begin{array}{l}\text { rms } \\
\text { error }\end{array}$ & $r^{2}$-value & $\begin{array}{l}\text { rms } \\
\text { error }\end{array}$ & $r^{2}$-value & $\begin{array}{l}\text { rms } \\
\text { error }\end{array}$ \\
\hline 1. & Magnitude & & & & & & & & \\
\hline Distributed & $(\mathrm{N}-\mathrm{s} / \mathrm{m})$ & 0.956 & 11.9 & 0.963 & 11.1 & 0.996 & 3.1 & 0.966 & 6.2 \\
\hline & (deg.) & 0.972 & 2.6 & 0.980 & 3.4 & 0.927 & 5.2 & & \\
\hline 2. & Magnitude & & & & & & & & \\
\hline $\begin{array}{l}\text { Total } \\
\text { method }\end{array}$ & $\begin{array}{l}(\mathrm{N}-\mathrm{s} / \mathrm{m}) \\
\text { Phase }\end{array}$ & 0.968 & 10.3 & 0.955 & 13.4 & 0.951 & 11.5 & 0.958 & 8.1 \\
\hline & (deg.) & 0.979 & 2.2 & 0.975 & 4.0 & 0.922 & 6.8 & & \\
\hline $\begin{array}{l}3 . \\
\text { Magnitude }\end{array}$ & $\begin{array}{l}\text { Magnitude } \\
(\mathrm{N}-\mathrm{s} / \mathrm{m})\end{array}$ & 0.968 & 10.1 & 0.949 & 15.1 & 0.958 & 14.0 & 0.959 & 8.8 \\
\hline method & $\begin{array}{l}\text { Phase } \\
\text { (deg.) }\end{array}$ & 0.975 & 2.5 & 0.973 & 4.4 & 0.930 & 6.6 & & \\
\hline $\begin{array}{l}4 . \\
\text { Real-part }\end{array}$ & $\begin{array}{l}\text { Magnitude } \\
(\mathrm{N}-\mathrm{s} / \mathrm{m})\end{array}$ & 0.936 & 14.7 & 0.943 & 16.1 & 0.963 & 10.1 & 0.952 & 9.2 \\
\hline method & $\begin{array}{l}\text { Phase } \\
\text { (deg.) }\end{array}$ & 0.975 & 3.0 & 0.976 & 4.0 & 0.919 & 7.1 & & \\
\hline
\end{tabular}


Table 4:

Average Inter-Subject STD Average Intra-Subject STD

\begin{tabular}{lcccccc}
\hline & Hand & Palm & Fingers & Hand & Palm & Fingers \\
\hline Magnitude (N-s/m) & 37.2 & 29.8 & 17.0 & 17.1 & 14.2 & 9.2 \\
Phase (deg.) & 7.2 & 8.1 & 8.9 & 3.3 & 3.5 & 4.5 \\
\hline
\end{tabular}


Table 5

Data Source

\begin{tabular}{|c|c|c|c|c|c|c|}
\hline Parameter & Unit & $\begin{array}{l}\text { Kinne et al. } \\
\text { (2001) }\end{array}$ & $\begin{array}{l}\text { Hesse } \\
(1989)\end{array}$ & $\begin{array}{l}\text { Marcotte } \\
\text { et al. } \\
(2005)\end{array}$ & $\begin{array}{c}\text { Hempstock \& } \\
\text { O’Connor } \\
\text { (1989) }\end{array}$ & $\begin{array}{c}\text { Kilberg } \\
(1995)\end{array}$ \\
\hline$M_{0}$ & $\mathrm{Kg}$ & 6.053 & 4.500 & 4.500 & 5.159 & 8.800 \\
\hline$M_{l}$ & $\mathrm{Kg}$ & 0.911 & 1.064 & 1.116 & 1.036 & 1.282 \\
\hline$M_{2}$ & $\mathrm{Kg}$ & 0.060 & 0.060 & 0.060 & 0.071 & 0.100 \\
\hline$M_{3}$ & $\mathrm{Kg}$ & 0.020 & 0.020 & 0.020 & 0.020 & 0.030 \\
\hline$M_{4}$ & $\mathrm{Kg}$ & 0.010 & 0.010 & 0.010 & 0.010 & 0.015 \\
\hline$K_{0}$ & $\mathrm{~N} / \mathrm{m}$ & 10,281 & 8,460 & 5,000 & 20,000 & 5,000 \\
\hline$K_{l}$ & $\mathrm{~N} / \mathrm{m}$ & 3,080 & 1,000 & 1,000 & 1,498 & 8,424 \\
\hline$K_{2}$ & $\mathrm{~N} / \mathrm{m}$ & 5,567 & 2,000 & 2,000 & 6,168 & 12,000 \\
\hline$K_{3}$ & $\mathrm{~N} / \mathrm{m}$ & 40,000 & 44,472 & 55,557 & 59,304 & 50,026 \\
\hline$K_{4}$ & $\mathrm{~N} / \mathrm{m}$ & 80,000 & 80,000 & 148,292 & 143,417 & 80,000 \\
\hline$C_{0}$ & $\mathrm{~N} \cdot \mathrm{s} / \mathrm{m}$ & 65 & 50 & 54 & 68 & 50 \\
\hline$C_{l}$ & $\mathrm{~N} \cdot \mathrm{s} / \mathrm{m}$ & 73 & 69 & 78 & 181 & 109 \\
\hline$C_{2}$ & $\mathrm{~N} \cdot \mathrm{s} / \mathrm{m}$ & 10 & 46 & 58 & 10 & 29 \\
\hline$C_{3}$ & $\mathrm{~N} \cdot \mathrm{s} / \mathrm{m}$ & 70 & 70 & 90 & 70 & 108 \\
\hline$C_{4}$ & $\mathrm{~N} \cdot \mathrm{s} / \mathrm{m}$ & 105 & 94 & 82 & 70 & 140 \\
\hline \multicolumn{7}{|c|}{ Natural frequency $(f)$ and damping ratio $(\xi)$} \\
\hline$F_{1}$ & $\mathrm{~Hz}$ & 7.4 & 7.3 & 5.8 & 10.3 & 6.0 \\
\hline$F_{2}$ & $\mathrm{~Hz}$ & 36.6 & 33.6 & 36.5 & 40.4 & 36.9 \\
\hline$F_{3}$ & $\mathrm{~Hz}$ & 190.1 & 186.1 & 251.9 & 231.8 & 152.8 \\
\hline$\xi_{l}$ & & 0.25 & 0.29 & 0.41 & 0.39 & 0.25 \\
\hline$\xi_{2}$ & & 0.36 & 0.41 & 0.44 & 0.49 & 0.40 \\
\hline$\xi_{3}$ & & 0.80 & 0.99 & 0.74 & 0.39 & 0.88 \\
\hline
\end{tabular}


Table 6

\begin{tabular}{ccrr}
\hline Parameter & Unit & \multicolumn{1}{c}{$\begin{array}{c}\text { 1-DOF } \\
\text { model }\end{array}$} & $\begin{array}{r}\text { 2-DOF } \\
\text { model }\end{array}$ \\
\hline$M_{l}$ & $\mathrm{~kg}$ & 2.2 & 1.8 \\
$M_{2}$ & $\mathrm{~kg}$ & & 0.2 \\
$K_{l}$ & $\mathrm{~N} / \mathrm{m}$ & 5,500 & 3,400 \\
$K_{2}$ & $\mathrm{~N} / \mathrm{m}$ & & 83,000 \\
$C_{l}$ & $\mathrm{~N} \cdot \mathrm{s} / \mathrm{m}$ & 240 & 150 \\
$C_{2}$ & $\mathrm{~N} \cdot \mathrm{s} / \mathrm{m}$ & & 130 \\
\hline
\end{tabular}


Fig. 1

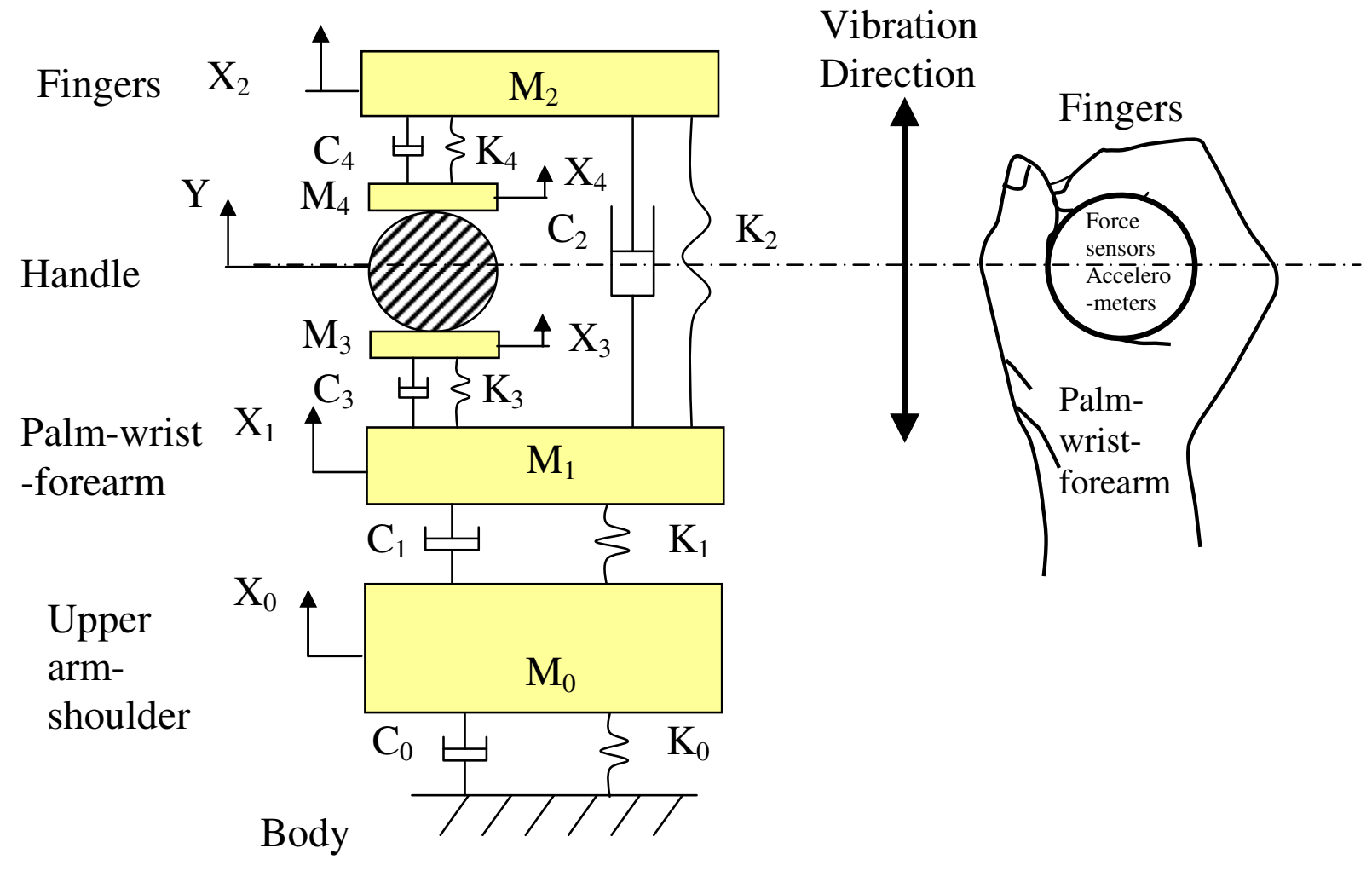


Fig. 2

- Experimental data $\longrightarrow$ Distributed method $\longrightarrow$ Total method

$\longrightarrow$ Magnitude method _ - - - Real part method

Magnitude
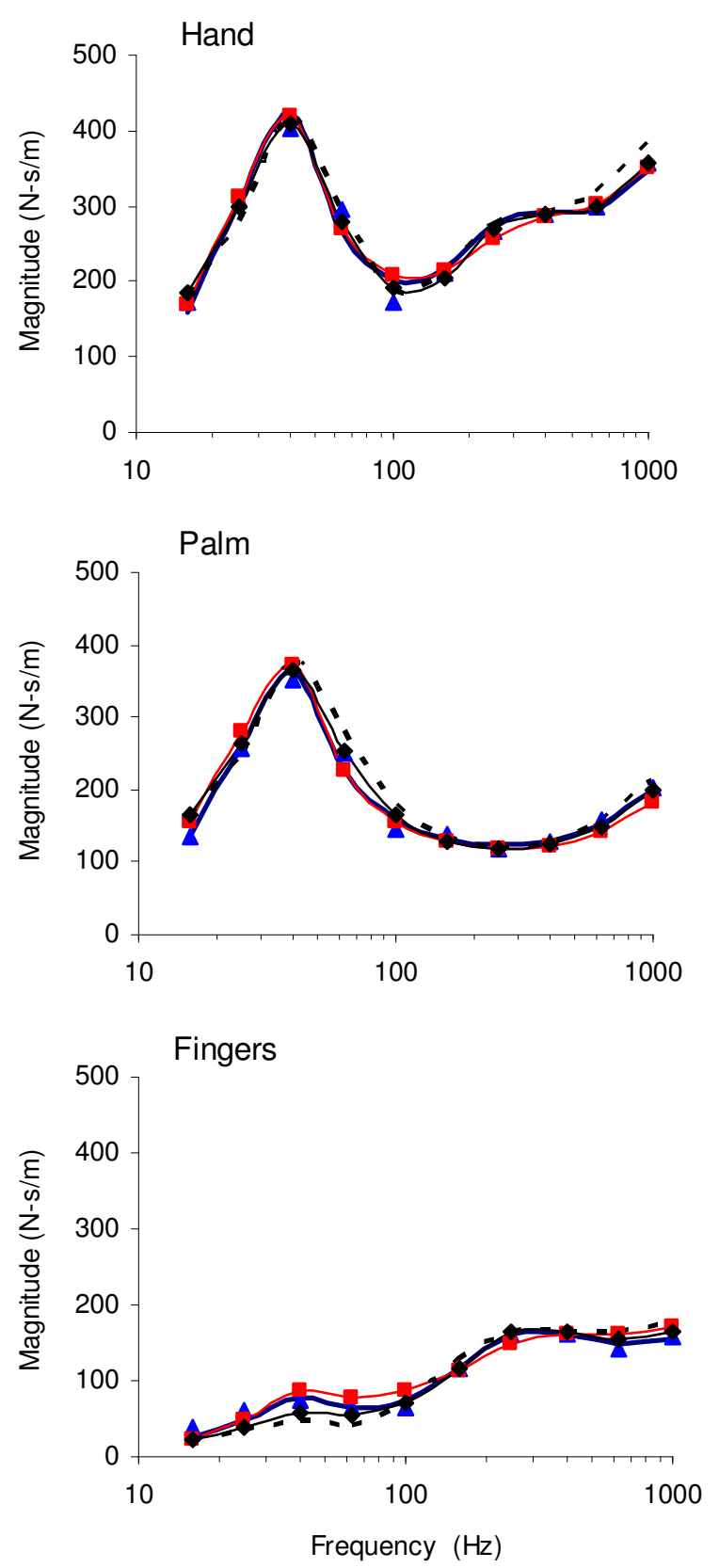

Phase
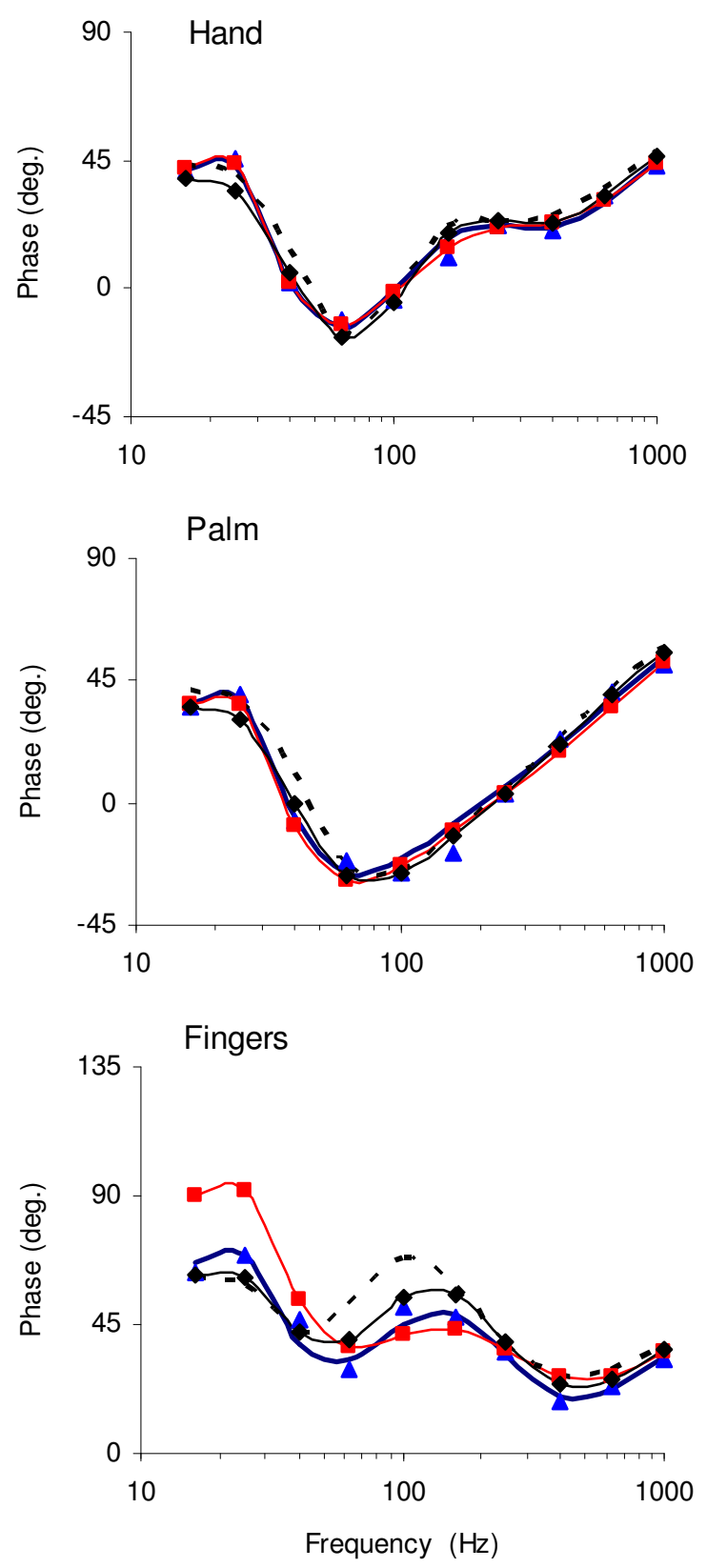
Fig. 3

\ Experimental data $\longrightarrow$ Distributed method $\longrightarrow$ Total method

$\longrightarrow$ Magnitude method _ - - - Real part method

Magnitude
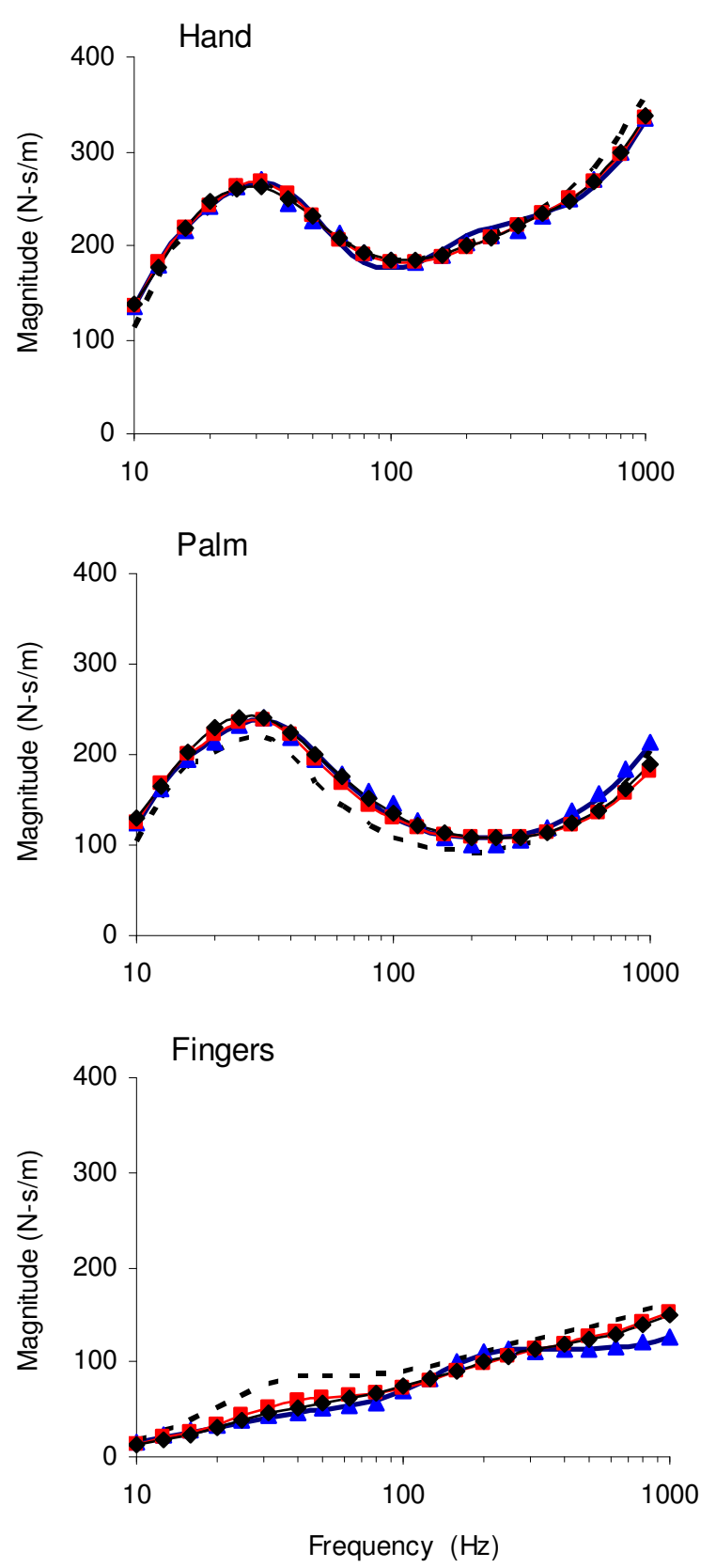

Phase
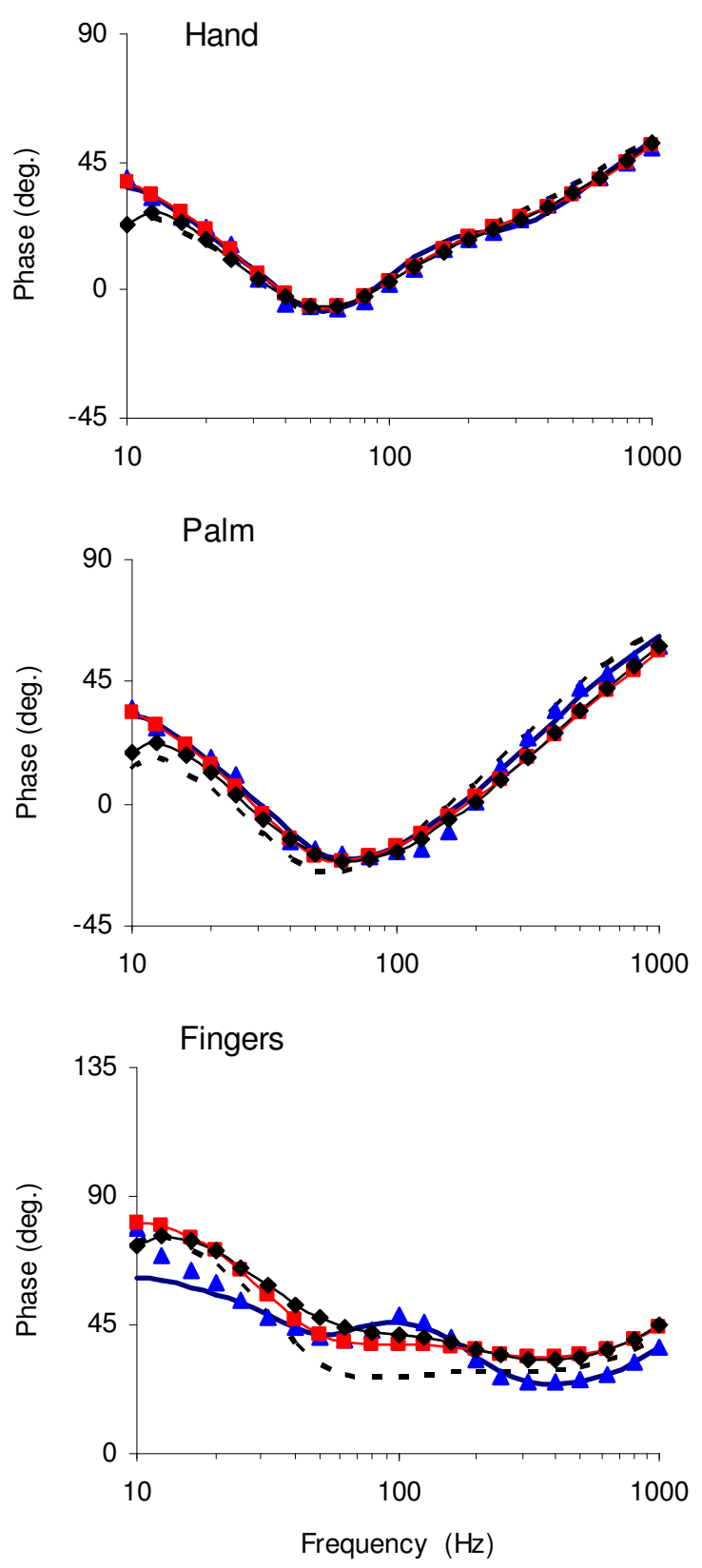
Fig. 4

\ Experimental data $\longrightarrow$ Distributed method $\longrightarrow$ Total method

$\longrightarrow$ Magnitude method _. - - Real part method

Magnitude
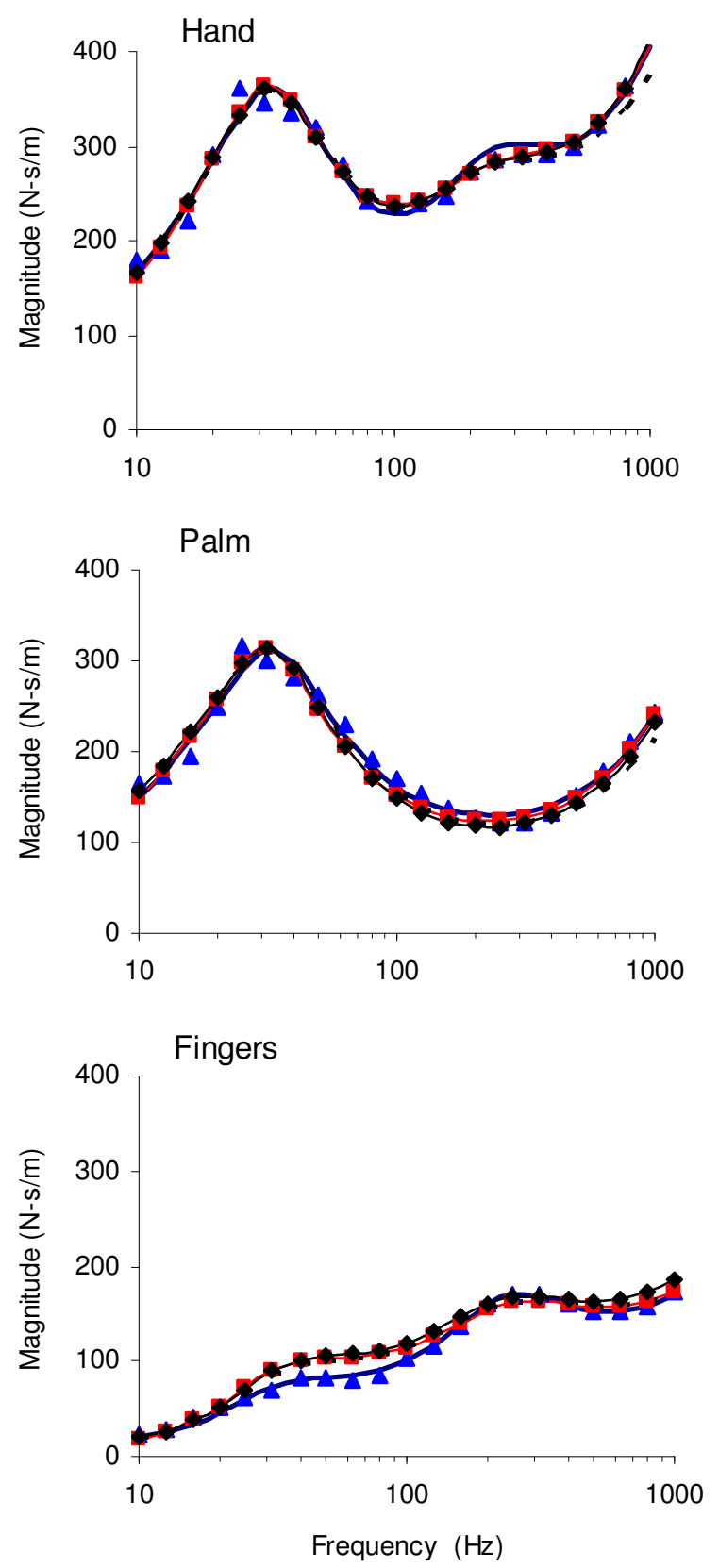

Phase
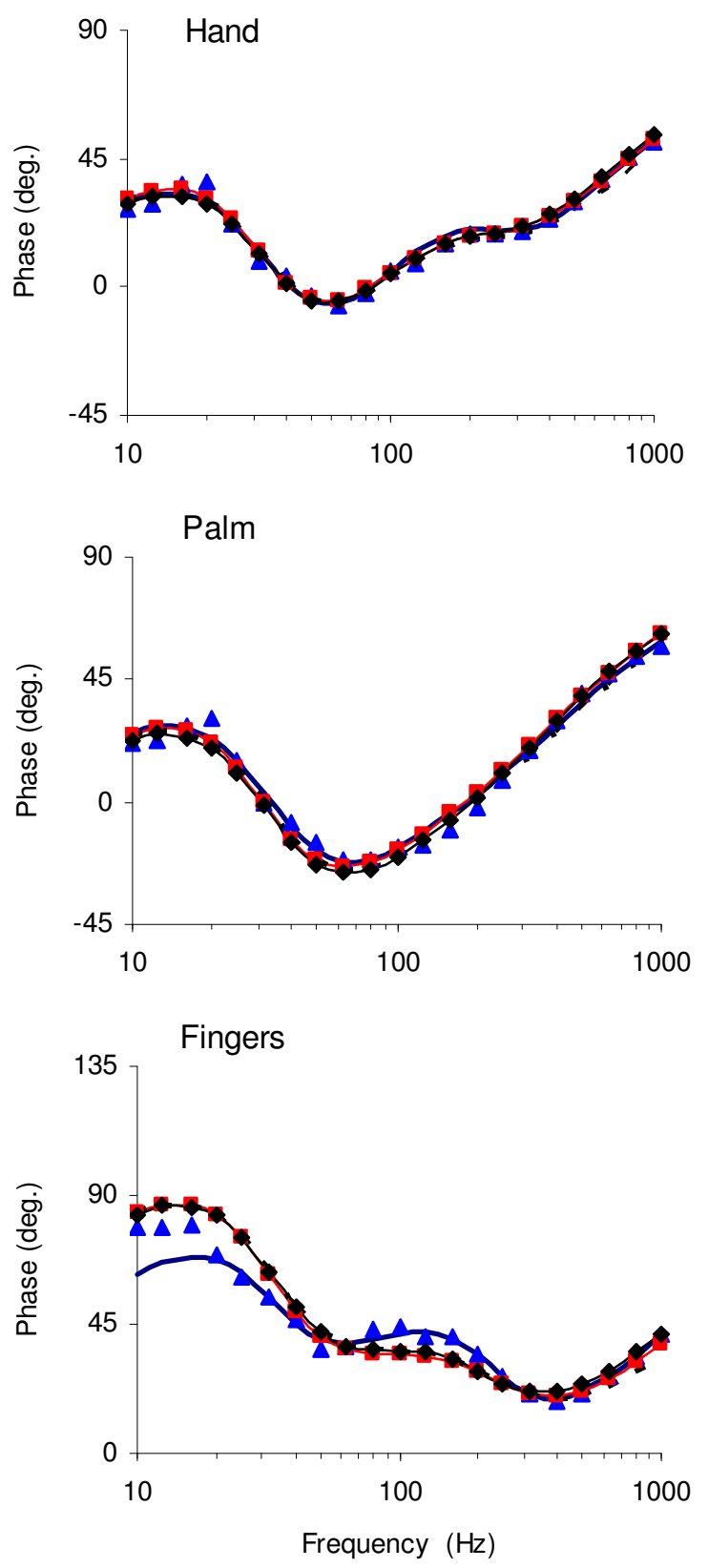
Fig. 5
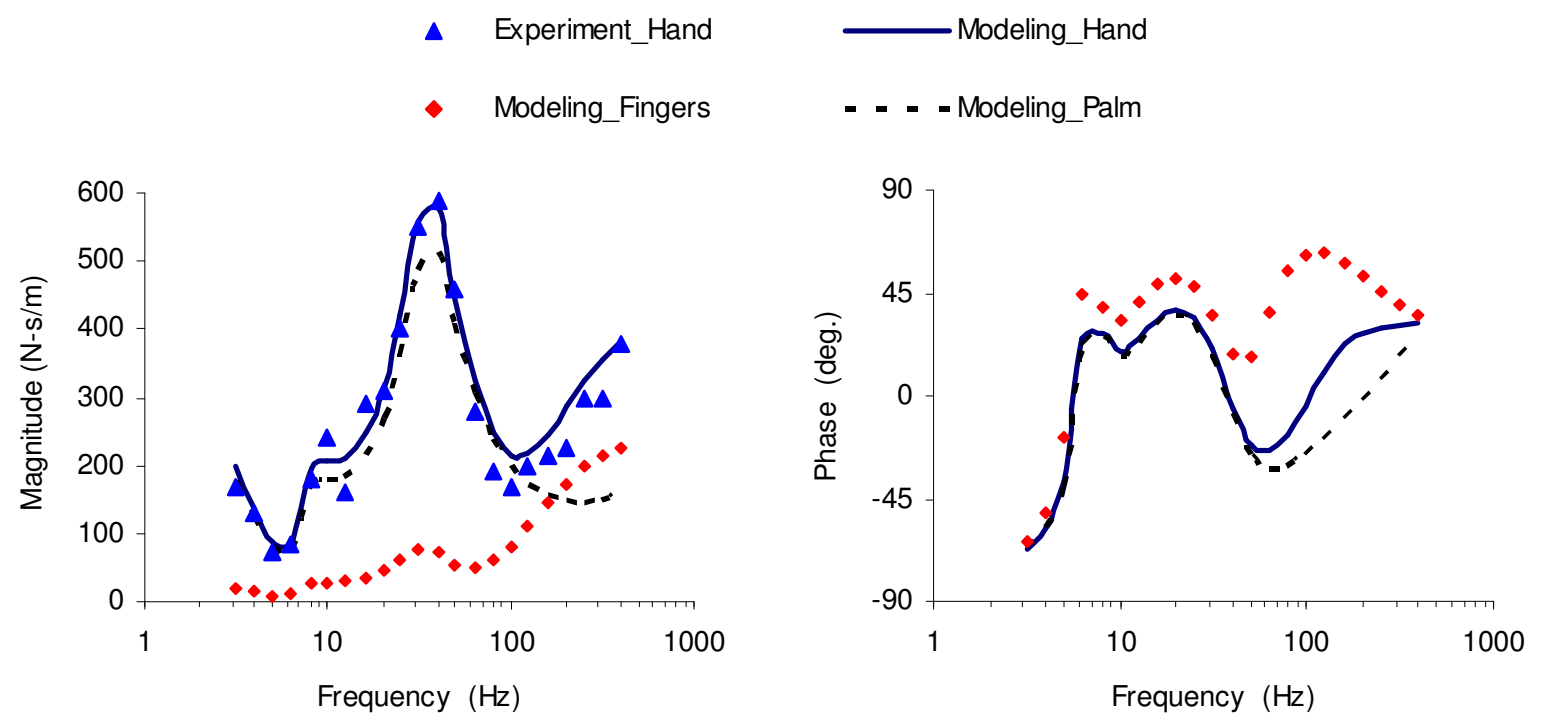
Fig. 6

- Experiment_Hand

- Modeling_Fingers

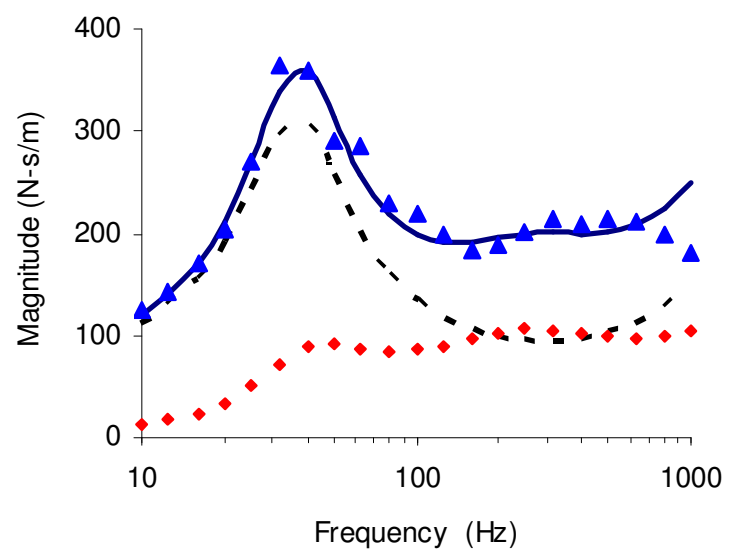

Modeling_Hand

- - - Modeling_Palm

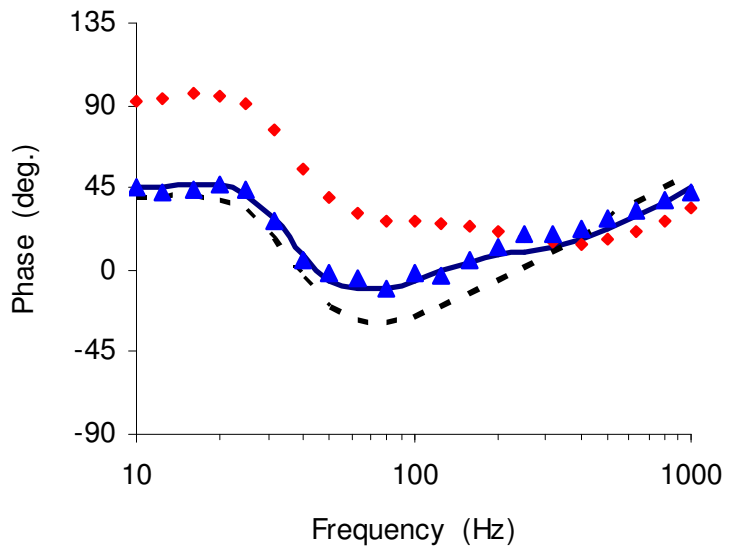


Fig. 7:

- Experiment_Hand

- Modeling_Fingers

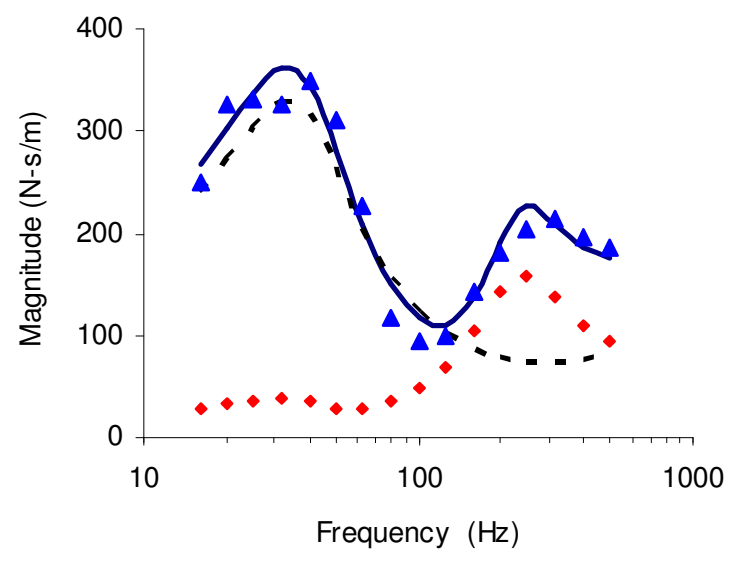

—Modeling_Hand

- - - Modeling_Palm

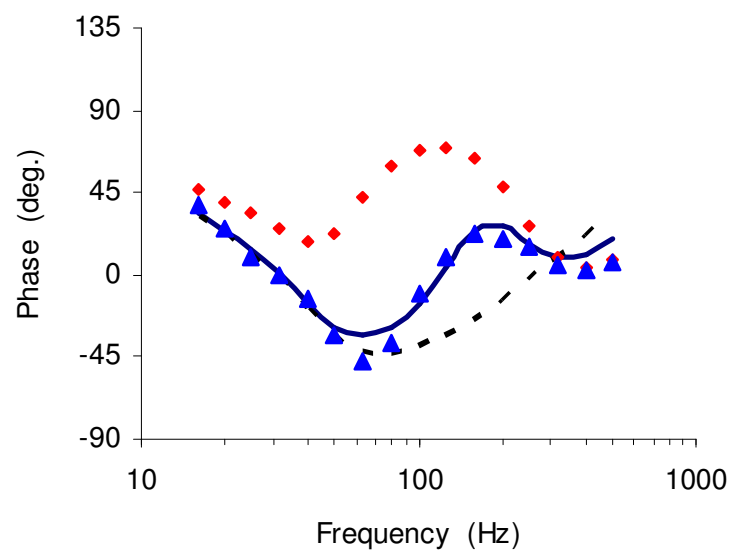


Fig. 8:

- Experiment_Hand

- Modeling_Fingers

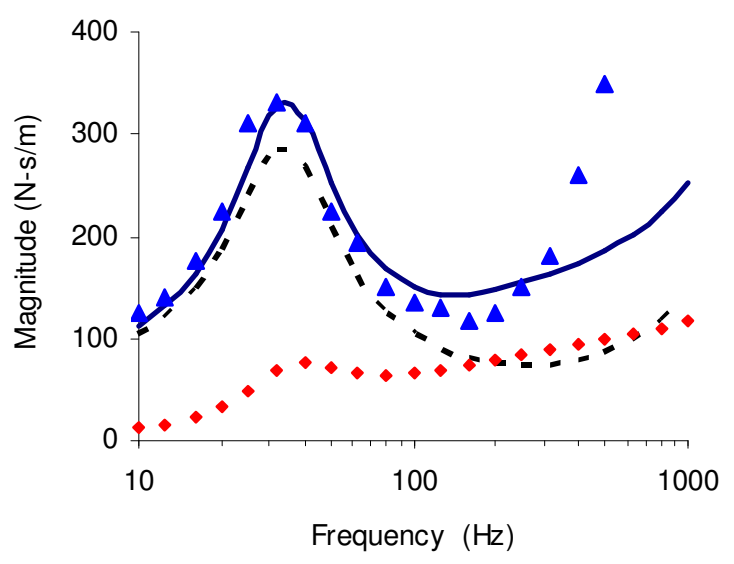

- Modeling_Hand

- - - Modeling_Palm

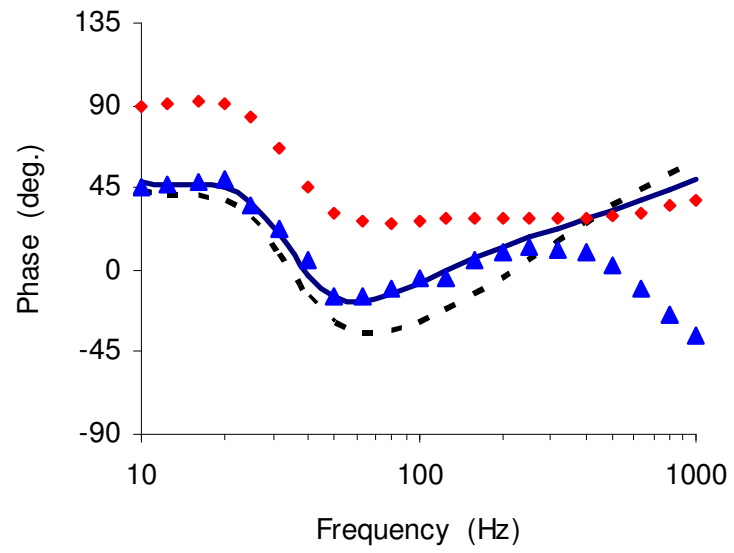


Fig. 9:

- Experiment_Hand

- Modeling_Fingers

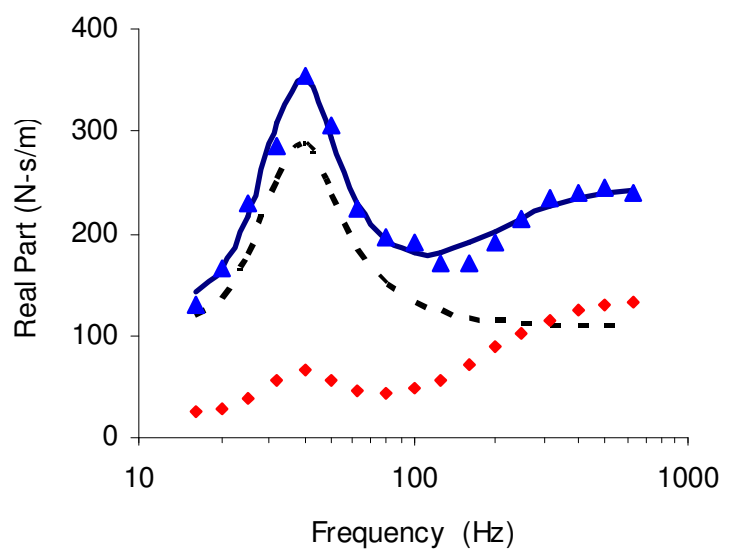

Modeling_Hand

- - - Modeling_Palm

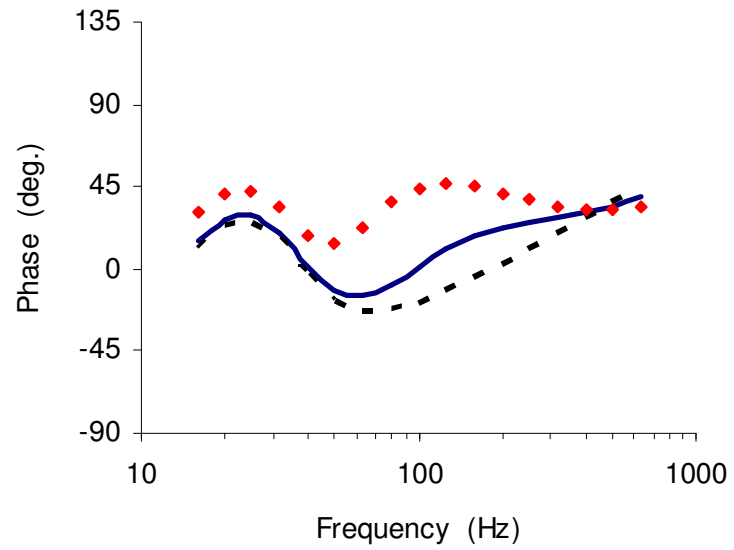


Fig. 10:
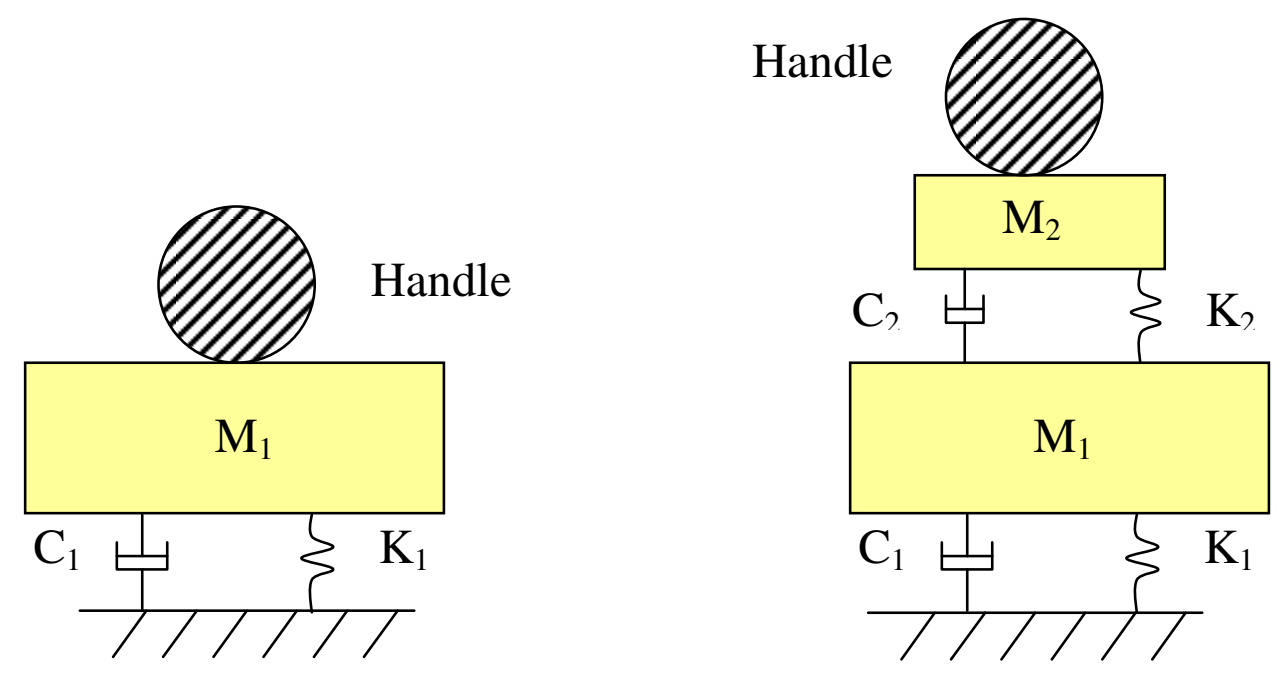

(a) 1-DOF model

(b) 2-DOF model 
Fig. 11:

$\triangle \quad$ Experiment (Kinne et al., 2001) $\quad$ Estimated in this study (Fig.5)
2-DOF model
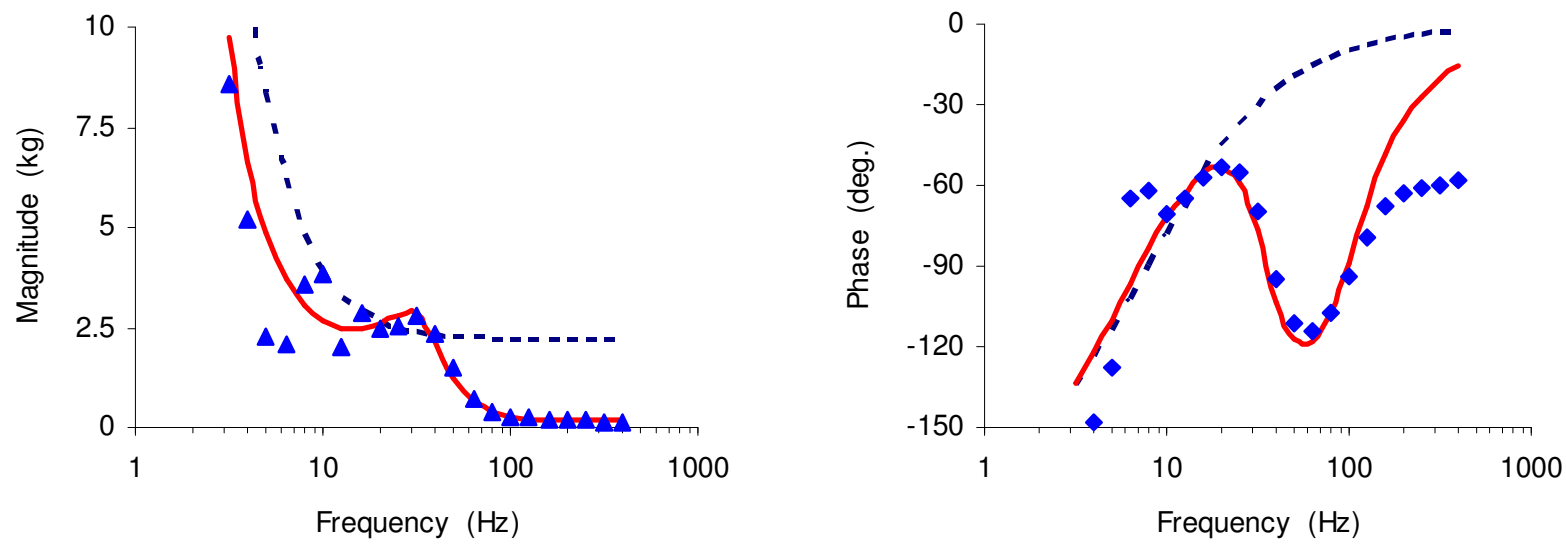